\title{
Nunca ha estado la filosofía más cerca de nosotros: la pandemia del COVID-19, epistemología y ética*
}

\section{PHILOSOPHY HAS NEVER BEEN CLOSER TO US: COVID-19 PANDEMIC, EPISTEMOLOGY AND ETHICS}

\author{
Ricardo Braun \\ Universidad de Lima \\ rbraun@ulima.edu.pe \\ https://orcid.org/0000-0002-0547-9618
}

\section{RESUMEN}

En este artículo demuestro la importancia de la discusión tanto académica como política de la filosofía en relación con la pandemia, con énfasis en los problemas epistemológicos y éticos. En un sentido popular, la filosofía produce la impresión de ser una tarea seguramente importante e interesante para sus practicantes, pero inútil para la mayoría de las personas. Nada más lejos de la realidad. Por el contrario, como lo demuestro, nuestra concepción de la actividad científica, del manejo de los datos y resultados de la investigación sobre la pandemia es el resultado de una larga tradición filosófica preocupada por la interrogante acerca de la obtención del conocimiento, si este fuera posible. En línea con las conclusiones que David Hume ofreció hace más de doscientos años, seguimos confiando discretamente en nuestras inducciones con un nivel de probabilidad, pero nunca de certeza. A eso tenemos que añadir las conclusiones que recientemente incorporan teorías como la del "efecto cisne negro". Se exploran, además, las consecuencias éticas que suponen las decisiones políticas, y se concluye que, en este y otros casos en el futuro, mejor será pensar como filósofos, no como políticos tradicionales.

\section{ABSTRACT}

In this essay, I show that academically and politicly, it is vital that we discuss as philosophers in relation to the pandemic, particularly in epistemology and ethics. For many, philosophy seems to be a futile intellectual activity, important and exciting just for professionals, but of no use to all the rest of us. Nothing could be further from reality. On the contrary, I demonstrate that philosophy lies well and healthy in the core of scientific method and justification, from Hume onwards. We have a long-standing tradition of questioning the basis of knowledge and if it is at all possible. From Hume's skeptical answer to induction, we have to add the contemporary theory of the black swan effect. I explore the moral consequences of political decisions, concluding that in this pandemic, such as in similar future situations, we would be better off thinking like philosophers and not like traditional politicians.

KEYWORDS: COVID-19 pandemic, philosophy, epistemology, ethic

PALABRAS CLAVE: pandemia del COVID-19, filosofía, epistemología, ética

* Agradezco al Programa de Estudios Generales por el auspicio para escribir este artículo. 
Los filósofos son quizás de los grupos sociales que más han practicado el autoaislamiento.

Charlotte Blease, Escuela de Medicina de Harvard

\section{INTRODUCCIÓN}

La filosofía como actividad académica y profesional goza de respeto. Pero se percibe como una actividad seguramente interesante e importante para los practicantes, pero no para los demás. Puede ser vista como decorativa, pero pocas veces útil y relevante. Nada más lejos de la verdad.

Si bien es cierto que solo un filósofo escribió acerca de las epidemias en el pasado (Camus y La peste), y muchos otros murieron en una de ellas (Ockham, Fichte, Hegel y otros, por ejemplo), en esta pandemia, y gracias a los accesibles medios de difusión, la filosofía no ha estado ajena a los problemas humanos ni en el pasado ni ahora. El problema es que no se tienen presentes los métodos y estilos que nos enseñaron en las clases de filosofía. El otro problema es que muchos no tomaron las clases de filosofía.

La filosofía no ofrece soluciones prácticas, como el tipo de vacuna que es eficaz, ni tampoco nos indica el orden de distribución de las vacunas. Pero nos enseña cómo tomar esas decisiones de la mejor manera. Por eso en este artículo quiero ofrecer, en forma introductoria, la manera como hacemos las cosas en filosofía. En la primera parte, explicaré la importancia del método que todo laboratorio científico utiliza para llegar a las vacunas: el método inductivo. Este es uno de los capítulos centrales de cualquier curso introductorio de epistemología. Veremos que no es el nombre de la vacuna lo que proporciona la epistemología, sino por qué deberíamos tener confianza en una u otra fórmula. Y qué recomendaciones deberíamos valorar. En la segunda parte, discuto la importancia de las preguntas éticas con respecto a nuestro actuar durante la pandemia. Sostengo que las autoridades políticas deberían tener una instrucción teórica sobre el modo de tomar decisiones morales. Porque esas teorías existen y sí, por ser filosóficas, son muy prácticas y útiles.

I

\section{LA INDUCCIÓN HUMANA Y EL “EFECTO CISNE NEGRO”}

Una de las lecciones que deberían estar aprendidas después de casi doscientos cincuenta años de haberse publicado la obra del filósofo escocés David Hume es la naturaleza y las limitaciones de la inducción como el método científico prevalente en la actividad 
científica. Desde el paso de la deducción por la inducción en el estilo cognitivo que Galileo nos legó, la actitud escéptica de Hume se instaló en la metodología científica y no se puede ni se debe evitar.

Las recomendaciones que se empezaron a indicar con respecto a la prevención del COVID-19 cambiaban constantemente y provocaban una sensación de desconocimiento acerca de la potencialidad de contagio y letalidad de esta enfermedad. Recientemente, el médico estadounidense Anthony Fauci es, nuevamente, objeto de acusaciones y cuestionamientos acerca de su autoridad como experto mundial en infecciones y epidemias.

Fauci se hizo muy conocido por su frontal combate al virus del VIH (que causa el sida) desde sus inicios en la década de 1980, y junto a los diferentes laboratorios que fueron pioneros en el desarrollo de los tratamientos, lograron convertir una pandemia incurable en una enfermedad crónica con visos de ser, quizá en algunas décadas, una enfermedad curable. Quizá.

Ese término no gusta a las personas, porque no entendieron su clase sobre los límites de la inducción en el curso de Epistemología. 0 no llevaron el importante curso de Filosofía. Las religiones nos traen el confort de certezas incuestionables. Descartes lo intentó para la filosofía y llegó solamente a la certeza del yo pensante. Gran consuelo, pero lo condena al solipsismo cognoscitivo. Kant (1783/1999) encontró en Hume un desafío digno de ser enfrentado al confesar que "lo interrumpió del sueño dogmático", como indica en el "Prefacio a los prolegómenos". Pero, luego de Hume, el escepticismo acerca de las conclusiones de las inferencias inductivas se instaló permanentemente en el estilo y métodos que la ciencia contemporánea no solo acepta, sino promueve. Fauci es un buen discípulo del escepticismo de Hume.

Fauci es un referente obligado de la infectología, una especie de libro de texto tanto por sus investigaciones como por su práctica clínica que continúa a sus 80 años. Pero su función como director del área de alergias y enfermedades infecciosas en un hospital de Estados Unidos es lo que le ha ganado amigos y enemigos en el mundo entero, dada su influencia como autoridad científica. En el mundo alejado de la ciencia se le conoce por igual, pero no por el método que él representa. La última acusación era de haber conducido al mundo, afectado por el COVID-19, por el camino equivocado cambiando constantemente de recomendaciones acerca de la prevención y tratamiento de este mal. La más saltante fue la sugerencia, al principio de la pandemia, de no usar mascarillas.

En febrero del 2020, en un intercambio de correos electrónicos entre Fauci y el ministro de Salud de los Estados Unidos, este afirmó que "las mascarillas realmente son para las personas infectadas, para que prevenga el contagio a las personas no infectadas y no tanto para proteger a las personas no infectadas del contagio"; y añadió que las mascarillas "no son realmente efectivas en protegernos del virus, porque es 
suficientemente pequeño para atravesar la tela" (Why are People Talking about Dr. Anthony Fauci's Emails?, 2020).

Fauci contesta lo que toda persona formada científicamente sabe: conocemos más acerca de un fenómeno conforme lo vamos experimentando. Al principio de la pandemia se sabían algunas características del virus, su potencial de contagio, medios de contagio, letalidad y otros. Pero, conforme se seguían recolectando datos durante los meses siguientes al brote de la pandemia, fueron cambiando las recomendaciones, precisamente a partir de la evidencia encontrada. De esa manera, para toda persona que quisiera información, la oficina de Fauci actualizaba las recomendaciones, en algunos casos, semanalmente. $Y$ este constante cambio no es otra cosa que nuestra práctica diaria en los laboratorios experimentales, en nuestros trabajos de campo y en la construcción de teorías. Lo que conocemos es lo que conocemos hoy. Mañana no podemos tener certeza - como Hume (1751/1980) sostiene - de que el sol saldrá.

Uno de los problemas centrales en la filosofía de la ciencia es el de la justificación del proceso lógico conocido como inducción. Este problema fue analizado por Hume, quien notó que, obviamente, no podemos conocer todas las ocurrencias de un fenómeno determinado en cualquier tiempo y espacio. Por ello, tendemos a conocer el mundo a partir de muestras individuales y generalizamos hacia un todo. Es de esta manera como se realiza gran parte de la actividad científica, especialmente a partir de Galileo en el siglo XVI hasta nuestros días. En su libro Opticks (1704), Newton defiende la inducción como el mejor método experimental para el estudio de la naturaleza y sostiene que tanto mayor sea la posibilidad de generalización, tanto más fuerte será la fuerza del argumento. Así pues, la inducción es un tema central en el método científico y es precisamente por esto que la crítica a la inducción de Hume ha tenido tanta repercusión en las discusiones de la metodología científica. Las críticas a Fauci son el resultado de haber desaprobado el examen de Epistemología Humana.

Los argumentos en lógica se dividen en deductivos e inductivos. Los deductivos son aquellos cuyas conclusiones se siguen necesariamente de las premisas; los inductivos, aquellos cuyas conclusiones se siguen, probablemente, de las premisas. Un clásico argumento deductivo es el llamado silogismo:

1. Todos los humanos son mortales.

2. Sócrates es un humano.

Por lo tanto:

3. Sócrates es mortal.

Se puede ver que la conclusión se sigue con certeza de las premisas dadas. Sin embargo, en la deducción lógica no se puede saber si la conclusión es verdadera porque 
no se puede saber si las premisas son verdaderas. En efecto, ¿cómo sabemos que "todos los humanos son mortales" o que "Sócrates es humano"? Lo único que la deducción nos proporciona es una certeza en la relación entre premisas y conclusión, pero ninguna información empírica.

En la inducción, en contraste, se parte de premisas singulares para llegar a una conclusión generalizadora. El ejemplo clásico es el siguiente:

1. Todos los cisnes que he observado son blancos.

Por lo tanto:

2. Todos los cisnes son blancos.

En la inducción procedemos de lo singular (instancias individuales observadas) a lo universal. Pero se ve que la conclusión no proporciona certeza. Bastaría que un cisne no fuera blanco para que la conclusión sea falsa. A pesar de esta limitación, la ciencia empírica utiliza a diario la inducción como parte de su metodología. Y no solo la ciencia, sino nosotros mismos en nuestro quehacer cotidiano. Solemos inferir conclusiones a partir de experiencias pasadas, por ejemplo:

- Los fumadores son personas que están en mayor riesgo de desarrollar cáncer y otras enfermedades, de manera que si no fumo, estaré en menor posibilidad de adquirir cáncer de pulmón y otras enfermedades.

- Las pruebas de sangre que han sido tomadas varias veces han revelado mi estado de salud en el pasado, de manera que puedo confiar en que la presente muestra de sangre indique mi estado de salud actual.

- Esta aerolínea ha tenido pocos accidentes, de manera que puedo confiar en que el vuelo de esta mañana será seguro.

Una forma de inferencia que se relaciona con la inducción es la llamada proyección. En una proyección se infiere a partir de un número observado de casos para llegar a una predicción acerca del siguiente caso, no a una generalización sobre todos los casos. Si hemos visto a un número de cisnes blancos, inferimos que el siguiente que veremos será blanco también.

En el supuesto de que todos nosotros, incluyendo a Hume, estuviésemos usando la inducción en la vida cotidiana y científica, ¿por qué deberíamos dudar de su justificación? Aquí viene Hume con toda su batería de cuestionamientos.

\section{¿Se puede justificar el proceso de inducción?}

Recordemos que no estamos argumentando acerca de cómo vivo mi vida, es decir, si sigo haciendo las inferencias cotidianas, sino sobre si tengo justificación para las inferencias 
que realizo. Hume mismo podría utilizar la inducción, pero sostendría que no está racionalmente justificada.

La pregunta central de Hume es la siguiente: ¿cómo a partir de un número finito de veces se puede predecir lo que ocurrirá en un número infinito de veces? Como hemos visto, es así como funciona la inducción: de un número finito de casos (instancias) generalizamos la forma en que se comportará un fenómeno particular de la naturaleza. Pero Hume cuestiona la justificación de este proceso.

Esta preocupación es muy importante. De hecho, el filósofo Bertrand Russell (1912/1997) propuso un ejemplo que mostraba la fragilidad de la inducción. Es el caso del pavo de Navidad.

El experto en la vida de los pavos, un pavo más viejo que los demás, encontró que en su primer día en la granja de pavos se le alimentaba a las nueve de la mañana. Como buen inductivista que era este experto, no se apresuró a llegar a conclusiones. Esperó hasta que tuviera un número importante de observaciones acerca de la hora de alimentación y empezó a relacionarla con los días de la semana. Así, puso un número de variables para relacionarlas con la hora de alimentación: días de la semana, clima, estación del año. Cada día añadía una observación a su ya larga lista. Finalmente, cuando estuvo satisfecho con el número de enunciados y observaciones, hizo la siguiente conclusión inductiva: "Siempre me dan de comer a las 9:00 a. m.". Lamentablemente, en la mañana de la víspera de la noche de Navidad no se le alimentó y le cortaron el cuello.

A Hume y, posteriormente, a la continuación de su negación de la justificación de la certeza de la conclusión de la inducción, se sumó Karl Popper en las primeras décadas del siglo xx, quien establecía que, dada la duda, mejor es tomar las conclusiones como conjeturas. Y eso nos lleva hasta nuestros días. Nuestro método científico se inspira básicamente en Hume y Popper.

Adicionalmente, y para atormentar aún más nuestras ansias de certezas, en el 2007 Nassim Taleb introdujo en las teorías matemáticas el concepto del "efecto cisne negro" para designar a todo evento impredecible, pero con consecuencias extremas. Hoy se utiliza rutinariamente en la inteligencia artificial para incorporar algunas variables que permitan al sistema aprender con elementos poco conocidos, pero eventualmente significativos (Taleb, 2008). El "efecto cisne negro" hace alusión al supuesto conocimiento basado en la incompleta información que se tenía acerca de los cisnes en Europa hasta que Willem de Vlamingh, durante su viaje a Australia en 1697, descubrió que, en efecto, existían cisnes negros. De manera que con las variables que manejamos hoy no podremos tener predicciones confiables, digamos, para los siguientes veinte años.

Así, el legado de Hume y de sus continuadores nos permite, primero, entender cómo se trabaja en la ciencia y, segundo, aceptar que la certeza no es un valor posible 
ni deseable. El mundo no tiene por qué satisfacer nuestras aspiraciones epistemológicas. El mundo está compuesto por fenómenos simples y fenómenos complejos. Son los segundos los que eluden nuestra comprensión total y muestran nuestra incapacidad de predicción exacta.

De manera que aprendiendo epistemología podemos tener una comprensión mejor de las medidas y recomendaciones que recibimos. Tomarlas en serio o no depende de nuestra actitud filosófica. Mis alumnos así lo entienden o espero que lo hagan. Esta fue su instrucción en el examen sobre epistemología en el curso Temas de Filosofía que dictamos a estudiantes de primer año:

Eres miembro del equipo consultor para el desarrollo de la vacuna contra el COVID19. Tu nombre es Karl Popper. Tienes que hacer una intervención acerca del tipo de pruebas que el equipo debe recomendar y de las precauciones sobre el empleo de las futuras vacunas. No puedes asistir a la reunión final. Escribe las palabras que serán leídas en esa reunión. Te indican que no pueden ser más de cinco líneas.

\section{LOS DILEMAS MORALES Y LA FILOSOFÍA}

Con o sin formación filosófica tendremos dilemas morales inevitablemente. Durante la pandemia los tenemos muy cerca, en casa algunas veces.

Cuando estudié Filosofía Moral, el curso incluía el conocido dilema moral creado por Philippa Foot, el llamado "dilema del tranvía". Un tranvía fuera de control está dirigiéndose hacia un riel en el que se encuentran amarradas cinco personas. Pero tenemos la posibilidad de cambiar el curso del tranvía desviándolo a otro riel en la intersección. El problema es que en esta otra vía está otra persona amarrada.

Siempre me pareció un poco tirado de los cabellos. No se podía preguntar qué hacen esas personas amarradas. Es un experimento mental basado en el estudio de posibilidades imaginarias pero posibles a fin de cuentas. Ese escenario ahora cobra patente realidad. Cambiemos los amarrados por pacientes en necesidad de camas con respirador artificial. El experimento se ha vuelto realidad y sin ninguna especulación estrambótica.

Y eso nos lleva a pensar que, en materia de políticas públicas, nuestras autoridades deben pensar como filósofos. Nuevamente, no tenemos las respuestas acerca de quién debe ocupar esa cama en la unidad de cuidados intensivos. Pero sí podemos tener criterios para que nuestra decisión tenga mejor justificación.

En la filosofía de influencia europea tenemos dos tradiciones dominantes. Una de ellas privilegia los actos moralmente evaluables como evaluables en sí mismos. Son 
teorías no consecuencialistas. 0 el acto es bueno o el acto es malo, independientemente de las consecuencias. Esa teoría está asociada a Immanuel Kant y a revisiones contemporáneas como la de John Rawls en su Teoría de la justicia (2010). En contraste, las teorías consecuencialistas ponen el énfasis en los resultados, los efectos de las acciones. Estas son las teorías que se nutren de los trabajos iniciales de Jeremy Bentham y John Stuart Mill, y tienen sus expresiones contemporáneas en filósofos como Peter Singer, particularmente en su relación con la inclusión de los animales en la comunidad moral.

Kant ofrece respuestas concretas a problemas muy concretos. ¿Debería llevarme todo el papel higiénico que queda en el anaquel? Tratemos de utilizar el imperativo categórico. No funciona. Si todos universalizamos la acción de llevarnos el limitado papel que queda, sería absurda la misma empresa de hacerlo. No alcanza para todos. Pero ninguna autoridad en el mundo ha hecho algún tipo de análisis no consecuencialista. En tiempos de pandemia, la ley de oferta y demanda se dejó fluir, imagino, esperando que "la mano invisible" se encargara de reponer el stock faltante.

Hemos tenido dilemas morales acerca de los derechos individuales versus los derechos colectivos. En los Estados Unidos la pregunta se hacía y las respuestas, que estaban sin dirección teórica, cobraron un deprimente número de víctimas. ¿Es el mandato de uso de mascarillas una obligación moral para quien no las quiere utilizar por respeto a su decisión individual?

Los políticos pueden apelar a teorías consecuencialistas en las que encontramos una sólida justificación para poner en suspenso, al menos temporalmente, la supremacía de los derechos individuales sobre los colectivos. Elegir, en contraste, una recomendación kantiana trae los resultados que mencioné.

Termino compartiendo un resumen, precisamente con relación a lo anterior y mejor descrito por Vittorio Bufacchi de la University College Cork de Irlanda:

Aquí tenemos una posible respuesta, quizás la lección más importante que la filosofía nos puede enseñar en este tiempo de crisis. Cada individuo tiene la responsabilidad de hacer lo que es correcto, independientemente de lo que nuestros gobiernos nos digan o fallan al no decirlo. El juramento hipocrático, primum non nocere, primero no harás daño, no se aplica exclusivamente a la institución médica; es un principio moral que todos debiéramos seguir, en nuestro mejor juicio, aun cuando los costos son altos, y eso incluye perder dinero en una vacación o en perdernos un espectáculo. (Como se citó en Humphreys, 2020) 


\section{REFERENCIAS}

Hume, D. (1980). Un ensayo sobre el conocimiento humano. Alianza Editorial. (Trabajo original publicado en 1751).

Humphreys, H. (26 de marzo del 2020). Coronavirus: How Can Philosophy Help Us in this Time of Crisis? The Irish Times. https://www.irishtimes.com/culture/ coronavirus-how-can-philosophy-help-us-in-this-time-of-crisis-1.4205889

Kant, I. (1999). Prolegómenos a toda metafísica futura que haya de poder presentarse como ciencia. Ediciones Istmo. (Trabajo original publicado en 1783).

Merck. (16 de junio del 2021). Dr. Fauci on the HIV/AIDS Epidemic: Ending It by 2030 is "doable". https://www.merck.com/stories/dr-fauci-on-the-hiv-aids-epidemic-ending -it-by-2030-is-doable/

Newton, I. (1704). Opticks: or, A Treatise of the Reflections, Refractions, Inflexions and Colours of light. https://library.si.edu/digital-library/book/optickstreatise00newta

Rawls, J. (2010). Teoría de la justicia. Fondo de Cultura Económica.

Russell, B. (1997). The Problems of Philosophy. Oxford University Press. (Trabajo original publicado en 1912).

Taleb, N. (2008). El cisne negro. El impacto de lo altamente improbable. Paidós.

Why are People Talking about Dr. Anthony Fauci's Emails? (2 de junio del 2020). BBC News. https://www.bbc.com/news/world-us-canada-57336280 